\title{
Prognostic impact of tumor-infiltrating CD276/Foxp3-positive lymphocytes and associated circulating cytokines in patients undergoing radical nephrectomy for localized renal cell carcinoma
}

\author{
KOTA IIDA, MAKITO MIYAKE, KENTA ONISHI, SHUNTA HORI, YOSUKE MORIZAWA, \\ DAISUKE GOTOH, YOSHITAKA ITAMI, SAYURI ONISHI, YASUSHI NAKAI, \\ SATOSHI ANAI, NOBUMICHI TANAKA and KIYOHIDE FUJIMOTO \\ Department of Urology, Nara Medical University, Nara 634-8522, Japan \\ Received October 19, 2018; Accepted February 14, 2019
}

DOI: $10.3892 / \mathrm{ol} .2019 .10057$

\begin{abstract}
Renal cell carcinoma (RCC) is an immunogenic tumor and pathological specimen generally contain large quantities of tumor-infiltrating lymphocytes (TILs). Numerous cell types and cytokines could affect the immune escape mechanism of tumor cells. The aim of the present study was to investigate the prognostic impact of TILs and the associated circulating cytokines on localized clear cell RCC following radical nephrectomy. A total of 87 patients who had undergone radical nephrectomy and were pathologically diagnosed with localized clear cell RCC were included. The present study evaluated the profile of TILs with immunohistochemical analysis of tumor specimens using a panel of antibodies [cluster of differentiation (CD)-4, CD8, CD80, CD86, CD276, and Forkhead box p3 (Foxp3)]. Counts of each TIL were compared with clinicopathological variables. Based on the results of immunohistochemical analyses, putative cytokines, including interleukin (IL)-6, IL-10, IL-17, interferon- $\gamma$, tumor necrosis factor (TNF)- $\alpha$, and transforming grow th factor (TGF)- $\beta$, were selected, and their levels in preoperative serum were measured by ELISA. The levels were compared with TIL counts in tumor specimens. High counts of the CD276 ${ }^{+}$and Foxp $3^{+}$TILs were identified as independent factors for poor prognosis for metastasis and local recurrence following radical nephrectomy ( $\mathrm{P}=0.033$ and 0.006 , respectively). A high CD276 ${ }^{+}$TIL count was associated with preoperative serum levels of TNF- $\alpha$ and IFN- $\gamma(\mathrm{P}=0.027$ and $\mathrm{P}=0.035$, respectively), whereas a high count of Foxp3 ${ }^{+}$TILs was associated with preoperative serum levels of TGF- $\beta(\mathrm{P}=0.021)$. High levels of TNF- $\alpha$ and TGF- $\beta$ were associated with recurrence-free survival $(\mathrm{P}=0.035$ and
\end{abstract}

Correspondence to: Professor Kiyohide Fujimoto, Department of Urology, Nara Medical University, 840 Shijo-cho, Kashihara, Nara 634-8522, Japan

E-mail:kiyokun@naramed-u.ac.jp

Key words: renal cell carcinoma, cluster of differentiation 276, Foxp3, tumor-infiltrating lymphocyte, cytokine
$\mathrm{P}=0.031$, respectively). Topical intra-tumoral immunoreaction and systemic immune status may be associated with patients with localized RCC. The topical induction of the CD276 ${ }^{+}$and Foxp $3^{+}$TILs was suggested to be associated with high levels of serum TNF- $\alpha$ and IFN- $\gamma$. Preoperative serum levels of TNF- $\alpha$ and TGF- $\beta$ could be simple and non-invasive biomarkers for risk stratification before radical surgery.

\section{Introduction}

Approximately $70 \%$ of patients with renal cell carcinoma (RCC) are diagnosed with localized RCC, and incidental detection of asymptomatic RCC is increasing with the widespread use of ultrasonography and computed tomography (CT) (1). Localized RCCs are treated by radical nephrectomy or partial nephrectomy. After complete surgical resection for localized RCC, 20 to $30 \%$ of patients progress to metastatic disease (2). The prognosis for patients with RCC is primarily dependent on disease stage, and patients with a high TNM stage have a poorer prognosis. Once RCC has metastasized, the 5-year survival rate is $<10 \%$ (3). The identification of prognostic markers would be useful to prevent localized RCC recurrence after surgery.

$\mathrm{RCC}$ is an immunogenic tumor and pathological specimens contain large numbers of tumor-infiltrating lymphocytes (TILs) (4). RCC can impair host antitumor immunity (5-7). Cancer cells express tumor-specific aberrant antigens and evade immune detection to survive by inducing immunosuppression or deriving survival signals from tumor-infiltrating immune cells $(8,9)$. Various cells and cytokines are involved in the immune escape of tumor cells. For instance, regulatory T cells (Tregs) and the B7 family are associated with tumor immune escape. Tregs play an important role in maintaining the stability of the immune system and tumor immune tolerance. Forkhead box p3 (Foxp3) is a specific transcription factor expressed in Tregs (10). The B7 family is composed of cell-surface proteins that regulate immune responses by delivering co-stimulatory or co-inhibitory signals through their ligands.

The correlation of Foxp3-positive cells or B7 family with patient clinicopathological features have been investigated 
in many cancers, including RCC (11-13). Tissue samples or blood samples only have tended to be used, with few studies examining both sample types. Furthermore, CD276 can increases the secretion of interferon-gamma (IFN $\gamma$ ) by activated T cells (14), and Foxp3 products interleukin (IL)-10, transforming growth factor- $\beta$ (TGF- $\beta$ ), and tumor necrosis factor-alpha (TNF $\alpha)(15)$. Although the correlation between TILs and associated cytokines has been reported, there is no consensus on their interactions.

Postoperative recurrence of RCC after radical surgery mostly depends on the presence of micrometastasis preoperatively. Here, we hypothesized the possible correlation of preoperative topical and systemic immunoreactions with the risk of micrometastasis. To evaluate topical and systemic preoperative immunoreactions, we investigated the correlation between the profile of TILs and preoperative serum cytokine levels. The aim of this study was to identify non-invasive and preoperative markers that could be valuable to predict the recurrence of localized clear cell RCC (ccRCC) after radical nephrectomy.

\section{Materials and methods}

Patients selection and data collection. Eighty seven patients who underwent radical nephrectomy for clinically localized ccRCC between January 2009 and December 2014 were included in this retrospective study. All patients underwent preoperative whole body computed tomography (CT) for tumor staging. The clinical stage was determined according to the TNM classification (16). Clinicopathological variables and laboratory data were extracted from medical records. The SSIGN score, which is an outcome prediction model for patients with ccRCC based on pathological stage, tumor size, nuclear grade, and necrosis (17), was evaluated as one of the clinicopathological variables. The histopathological review was conducted by an experienced uropathologist to determine the T category and Fuhrman grade (18), as well as the presence of necrosis, sarcomatoid variant, and lymphovascular invasion (LVI). All subjects gave their written informed consent for inclusion before they participated in the study. The study was conducted in accordance with the Declaration of Helsinki, and the protocol was approved by the Ethics Committee of Nara Medical University (Nara, China) (Project identification code: 1630, accepted: August 21, 2017).

Immunohistochemistry (IHC) staining. Resected tissue specimens were fixed in formalin, embedded in paraffin, and then subjected to IHC staining for the cell surface and immunological markers CD4, CD8, CD80 (B7-1), CD86 (B7-2), CD276 (B7-H3), and Foxp3 (a Treg marker). Paraffin blocks were cut and placed on Superfrost Plus microslides (Thermo Fisher Scientific, Inc., Yokohama, Japan). Sections were deparaffinized and citric acid buffer ( $\mathrm{pH}$ 6.0) antigen retrieval was carried out with autoclaving. IHC staining was performed using the Histofine ABC kit (Nichirei Biosciences, Tokyo, Japan) according to the manufacturer's instructions. Briefly, slides were incubated overnight at $4^{\circ} \mathrm{C}$ with monoclonal antibodies against CD4 (clone 4B12, ready-to-use; Nichirei Biosciences), CD8 (clone C8/144B, ready-to-use; Nichirei Biosciences), CD80 (clone EPR1157 (2), 1:500 dilution;
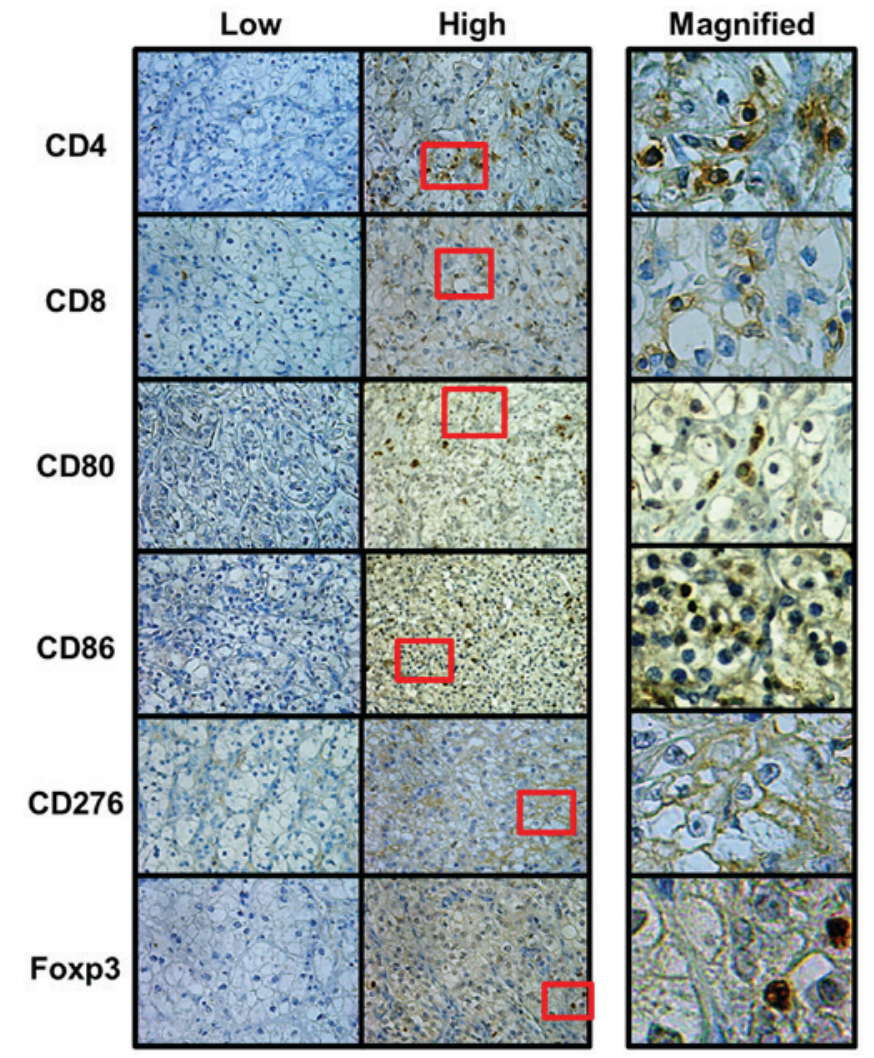

Figure 1. Representative images of tumors stained for each marker. Low group (left-hand column) and high group (middle column) are shown. The magnified images of the red squared area in the high group column are also shown on the right-hand side. Magnification, x1,000. CD, cluster of differentiation; Foxp3, Forkhead box p3.

Abcam, Cambridge, UK), CD86 (clone EP1158Y, 1:500 dilution; Abcam), CD276 (clone 6A1, 1:1000 dilution; Abcam), and Foxp3 (clone 236A/E7, 1:500 dilution; Abcam). The slides were counterstained with Mayer's hematoxylin, dehydrated, and sealed with a cover slide.

Expression of markers. All stained tissue samples were evaluated by two investigators ( $\mathrm{KO}$ and $\mathrm{YI}$ ) without knowledge of the patients' clinical records. One sample was divided into four randomly selected tumor areas at x400 magnification. The percentage of stained cells was calculated by taking the mean of percentage calculated by dividing a positive cell count by the total cell count of positive cell count and negative cell count. Specimens were classified into two groups (low and high) based on the staining population. The cutoff level of CD4 and CD8 was set at 20\%, and the cutoff level of CD80, CD86, CD276, and Foxp3 was set at 10\% $(13,19)$. The expression of Foxp3 was evaluated with the nucleus of tumor cells exhibiting immunoreactivity, and the expressions of other markers were evaluated with the cell membrane (Fig. 1).

Measurement of serum cytokines. Serum was collected from every patient in tubes before the operation and centrifuged at $1,000 \mathrm{x} \mathrm{g}$ for $15 \mathrm{~min}$. The supernatant was recovered and stored at $-80^{\circ} \mathrm{C}$ until analysis. Based on the result of the IHC analysis, six cytokines (IL-6, IL-10, IL-17, IFN- $\gamma$, TNF- $\alpha$, and TGF- $\beta$ ) were selected. Their profiles in preoperative sera were determined using the following ELISA kits: human IL-6 

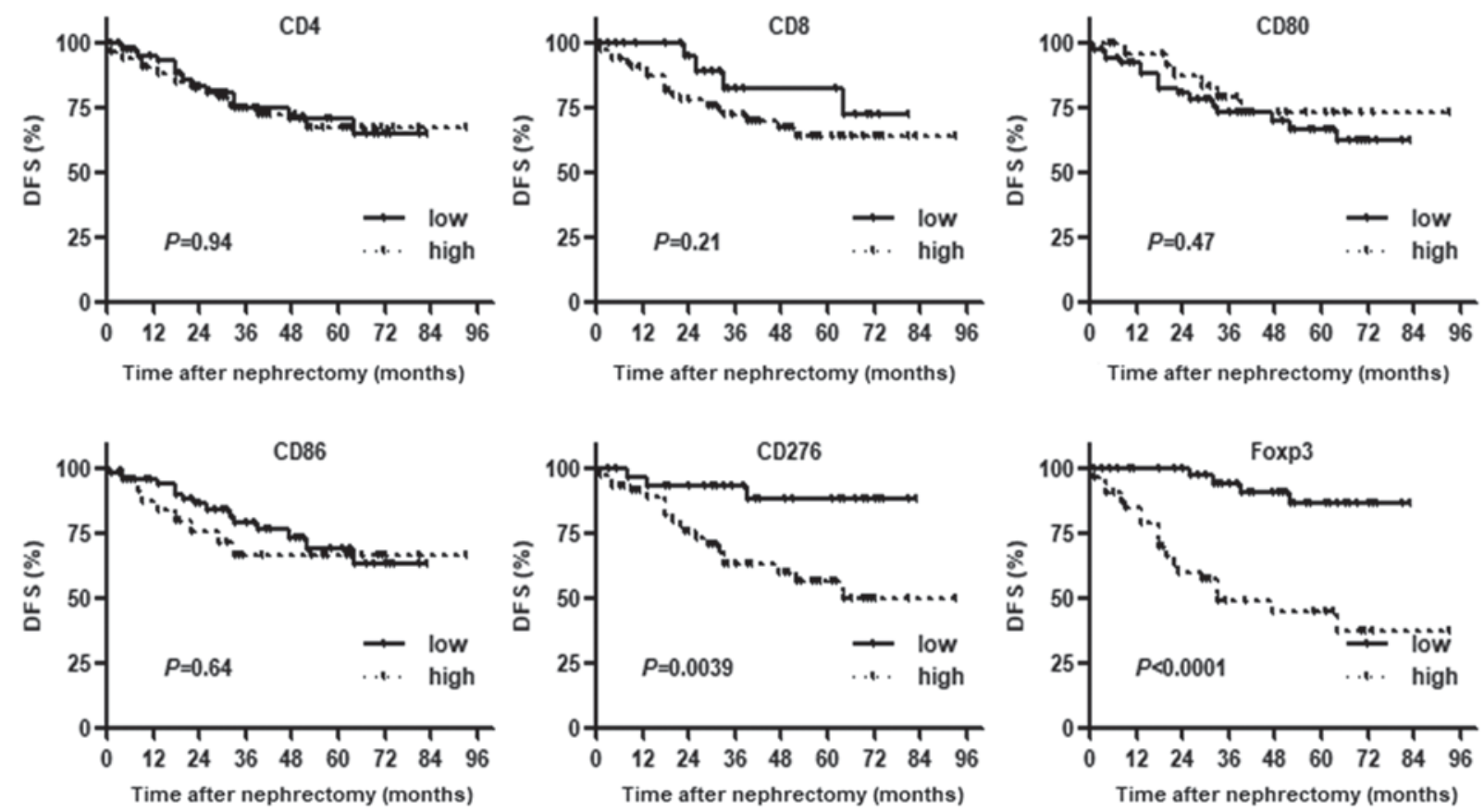

Figure 2. Kaplan-Meier curves for disease-free survival in all 87 cases. The patients with high counts of CD276 $6^{+}$or Foxp3 $3^{+}$tumor-infiltrating lymphocytes had a significantly higher risk of recurrence when compared with patients in the low group. CD, cluster of differentiation; Foxp3, Forkhead box p3; DFS, disease-free survival.

(950.030.096, Diaclone SAS, Besancon, France), human IL-10 (950.060.096, Diaclone SAS), human IL-17A (850.940.096, Diaclone SAS), TNF- $\alpha$ (950.090.096, Diaclone SAS), IFN- $\gamma$ (950.000.096, Diaclone SAS), and TGF- $\beta 1$ (DB100B, R\&D Systems, Minneapolis, MN, USA). A microplate reader (Tecan Systems Inc., San Jose, CA, USA) was used to measure the absorbance at $450 \mathrm{~nm}$.

Statistical analyses. The statistical analyses were performed with SPSS for Windows (version 20.0; IBM, Corp., Armonk, NY, USA). Figure plotting was performed using GraphPad Prism 5.0 (GraphPad Software, Inc., La Jolla, CA, USA). The correlations between the counts of TILs and clinicopathological characteristics were analyzed using the Mann-Whitney $\underline{\mathrm{U}}$ test, Chi-square test, or Fisher's exact test as appropriate. The correlations between the counts of TILs and serum levels of cytokines were analyzed using the Mann-Whitney U test. Disease-free survival (DFS) was used as an endpoint, and Kaplan-Meier survival curves were plotted and compared using the log-rank test for univariate analysis. The Cox regression model was used for multivariate DFS analysis. $\mathrm{P}<0.05$ was considered to indicate a statistically significant difference.

\section{Results}

Patient characteristics. The median follow-up period after radical nephrectomy for the DFS analysis was 39.9 months (range, 4-93 months). During the follow-up period, 22 patients (25.3\%) experienced recurrence, which was defined as local recurrence or metastasis involving lymph node, bone, lung, or other sites. The median follow-up period after radical nephrectomy for the overall survival analysis was 48.8 months (range 6-100 months). During the follow-up period, 14 patients (16.1\%) died.

Expression of TIL counts and clinical course. Patients were classified into low and high groups based on staining (Fig. 1). Univariate analysis with Kaplan-Meier curves and log-rank test analysis showed that patients with high counts of CD276 ${ }^{+}$ or Foxp $3^{+}$TILs had a significantly higher risk of recurrence after nephrectomy compared with patients with low counts of $\mathrm{CD}_{276^{+}}$or Foxp3 $3^{+}$TILs. With regard to the other markers, there were no significant differences in DFS between the two groups (Fig. 2).

Correlation between CD276 or Foxp3 counts and clinicopathological variables. The baseline clinicopathological variables for the 87 cases and their association with the counts of $\mathrm{CD}_{276^{+}}$or Foxp3 ${ }^{+}$TILs are summarized in Table I. Patients with high counts of CD276 ${ }^{+}$TIL had a significantly high $\mathrm{pT}$ stage and were linked with the presence of LVI compared to patients in the low group (Table I). Moreover, patients with high counts of the Foxp3 $3^{+}$TIL had a significantly high pT stage and high SSIGN score compared to patients in the low group.

Prognostic factors of recurrence after radical nephrectomy. Cox univariate analyses showed that high pT stage, high SSIGN score, high counts of CD276 ${ }^{+}$TILs, and high counts of Foxp $3^{+}$TILs were factors for poor prognosis for recurrence (Table II). Multivariate analyses showed that high counts of the $\mathrm{CD}_{276^{+}}$and Foxp3 ${ }^{+}$TILs were independent factors for poor prognosis due to recurrence.

Correlation between TIL counts and preoperative serum level of cytokines. Based on the result of the 
Table I. Characteristics of clear cell renal cell carcinoma patients in dependent of CD276 and Foxp3 expression.

\begin{tabular}{|c|c|c|c|c|c|c|c|}
\hline \multirow[b]{2}{*}{ Variables } & \multirow[b]{2}{*}{ Total $\mathrm{n}$} & \multicolumn{3}{|c|}{ CD276 } & \multicolumn{3}{|c|}{ Foxp3 } \\
\hline & & Low & High & $\mathrm{P}$-value & Low & High & P-value \\
\hline $\mathrm{n}$ & 87 & 36 & 51 & & 53 & 34 & \\
\hline Sex & & & & $0.89^{\mathrm{a}}$ & & & $0.92^{\mathrm{a}}$ \\
\hline Male & 67 & 28 & 39 & & 41 & 26 & \\
\hline Female & 20 & 8 & 12 & & 12 & 8 & \\
\hline Age, median (range), years & 67 & $68.5(36-87)$ & $66.0(39-85)$ & $0.96^{\mathrm{b}}$ & $67(36-87)$ & $67.5(42-85)$ & $0.61^{\mathrm{b}}$ \\
\hline MSKCC & & & & $0.60^{\mathrm{a}}$ & & & $0.60^{\mathrm{a}}$ \\
\hline Good & 44 & 17 & 27 & & 28 & & \\
\hline Intermediate/poor & 43 & 19 & 24 & & 25 & 18 & \\
\hline pT category & & & & $0.0021^{\mathrm{a}}$ & & & $0.01^{\mathrm{a}}$ \\
\hline $\mathrm{T} 1$ & 32 & 21 & 11 & & 26 & 6 & \\
\hline $\mathrm{T} 2$ & 3 & 1 & 2 & & 2 & 1 & \\
\hline $\mathrm{T} 3 / 4$ & 52 & 14 & 38 & & 25 & 27 & \\
\hline SSIGN score & & & & $0.065^{\mathrm{a}}$ & & & $0.0083^{\mathrm{a}}$ \\
\hline$\leq 4$ & 58 & 28 & 30 & & 41 & 17 & \\
\hline$>4$ & 29 & 8 & 21 & & 12 & 17 & \\
\hline LVI & & & & $0.0039^{\mathrm{a}}$ & & & $0.91^{\mathrm{a}}$ \\
\hline LVI- & 42 & 24 & 18 & & 33 & 9 & \\
\hline LVI+ & 45 & 12 & 33 & & 20 & 25 & \\
\hline
\end{tabular}

${ }^{a}$ Chi-square test or Fisher's exact test, ${ }^{b}$ Mann-Whitney U test. MSKCC, Memorial Sloan Kettering Cancer Center; LVI, Lymphovascular invasion; CD, cluster of differentiation; Foxp3, Forkhead box p3.

immunohistochemical analysis, we focused on the association between CD276/Foxp3-positive lymphocytes and the circulating cytokines. Relationships with various cytokines have been reported in CD276/Foxp3-positive lymphocytes, where CD276 increases IFN $\gamma$ secretion by activated T cells (15) as well as Foxp3 products IL-10, TGF- $\beta$, and TNF $\alpha$ (16). Furthermore, levels of IL6 and IL17, which were associated with Th17, were also assessed because the balance of Th17 and Treg can be skewed in patients with RCC (20). Therefore, putative cytokines including IL-6, IL-10, IL-17, IFN- $\gamma$, TNF- $\alpha$, and TGF- $\beta$ were selected and their levels in the preoperative serum were measured. Patients with high counts of CD276 ${ }^{+}$TILs had significantly high serum levels of TNF- $\alpha$ and IFN- $\gamma$ compared to patients in the low group. Patients with high counts of Foxp $3^{+}$TILs had a significantly high serum level of TGF- $\beta 1$ compared to patients in the low group (Table III).

Prognostic value of preoperative serum level of TNF- $\alpha, I F N-\gamma$, and $T G F-\beta 1$. To identify preoperative blood-based tests useful in predicting prognosis, the association of TNF- $\alpha$, TGF- $\beta 1$, and IFN- $\gamma$ with prognosis was analyzed, since these three cytokines have been linked with the expression of CD276 ${ }^{+}$ or Foxp $3^{+}$TILs. Kaplan-Meier analysis revealed that patients with high serum levels of TNF- $\alpha$ and TGF- $\beta 1$ had a significantly higher risk of recurrence after nephrectomy compared to patients with low serum levels. There was no significant difference in IFN- $\gamma$ between the two groups (Fig. 3).

\section{Discussion}

In this study, we found that high counts of CD276 ${ }^{+}$and Foxp3 ${ }^{+}$ in tumor tissues were independent factors for the poor prognosis of visceral metastasis or local recurrence after radical nephrectomy for localized ccRCC. Moreover, we found that high preoperative serum levels of TNF- $\alpha$ and TGF- $\beta 1$ were also factors for poor prognosis.

Foxp3 belongs to the transcription factor Forkhead box family and is a master gene of Treg differentiation and a specific transcription factor expressed in Tregs. Foxp3 exists in the tumor microenvironment and is a negative factor that controls antitumor immunity by disrupting $\mathrm{T}$ cell increase (10). It has also been reported that the expression of tumor-infiltrating Foxp3-positive lymphocytes was associated with poor prognosis in several cancers, including lung (21), breast (22), liver (23), pancreatic (24), ovarian (25), and kidney cancer (26).

CD276 is a member of the B7 family, which comprises cell-surface proteins that regulate immune responses by delivering co-stimulatory or co-inhibitory signals through their ligands. B7-H3 is one of the most recently described members of the B7 family, so its function and binding partners have not yet been elucidated. Tumor-infiltrating CD276-positive lymphocytes have been associated with poor prognosis in several cancers, including lung (27), colon (28), and kidney cancer (29).

In this study, high counts of Foxp $3^{+}$TILs were associated with pT stage and SSIGN score, and high counts of CD276 
Table II. Univariate and multivariate analyses for disease-free survival of clinicopathological variables in patients with clear cell renal cell carcinoma.

\begin{tabular}{|c|c|c|c|c|c|c|}
\hline \multirow[b]{3}{*}{ Variables } & \multicolumn{6}{|c|}{ Disease-free survival } \\
\hline & \multicolumn{3}{|c|}{ Univariate } & \multicolumn{3}{|c|}{ Multivariate } \\
\hline & HR & $95 \% \mathrm{CI}$ & P-value & HR & $95 \% \mathrm{CI}$ & P-value \\
\hline Sex & & & 0.93 & & & \\
\hline Male & 1 & & & & & \\
\hline Female & 0.96 & $0.36-2.58$ & & & & \\
\hline Age, years & & & 0.73 & & & \\
\hline$<70$ & 1 & & & & & \\
\hline$\geq 70$ & 1.16 & $0.50-2.73$ & & & & \\
\hline MSKCC & & & 0.26 & & & \\
\hline Good & 1 & & & & & \\
\hline Intermediate/poor & 1.69 & $0.68-4.18$ & & & & \\
\hline pT category & & & 0.02 & & & 0.16 \\
\hline$\leq \mathrm{T} 2$ & 1 & & & & & \\
\hline $\mathrm{T} 3$ & 2.74 & $1.17-6.42$ & & 0.32 & $0.069-1.54$ & \\
\hline SSIGN score & & & 0.0023 & & & 0.30 \\
\hline$\leq 4$ & 1 & & & & & \\
\hline$>4$ & 4.19 & $1.67-10.54$ & & 1.65 & $0.64-4.26$ & \\
\hline LVI & & & 0.13 & & & \\
\hline- & 1 & & & & & \\
\hline+ & 1.92 & $0.83-4.44$ & & & & \\
\hline CD276 expression & & & 0.0039 & & & 0.033 \\
\hline Low & 1 & & & & & \\
\hline High & 3.48 & $1.49-8.12$ & & 3.76 & $1.12-12.67$ & \\
\hline Foxp3 expression & & & $<0.0001$ & & & 0.006 \\
\hline Low & 1 & & & & & \\
\hline High & 8.05 & $3.33-19.44$ & & 2.92 & $1.35-6.31$ & \\
\hline
\end{tabular}

HR, hazard ratio; CI, confidence interval; MSKCC, Memorial Sloan Kettering Cancer Center; LVI, Lymphovascular invasion; CD, cluster of differentiation; Foxp3, Forkhead box p3.

TILs were associated with pT stage and LVI. The SSIGN score is an outcome prediction model for patients with ccRCC treated with radical nephrectomy. The score is based on pathological stage, tumor size, nuclear grade, and necrosis (18). LVI, pT stage, and SSIGN score are important prognostic factors of RCC, but they cannot be evaluated preoperatively. Therefore, we focused on preoperative serum levels of several cytokines, which have been reported to be correlated with the recruitment of $\mathrm{CD} 276^{+}$cells and Foxp3 $3^{+}$cells.

The relationships between Tregs or CD276 and several cytokines have been reported previously. von Boehmer et al (30) reported that Tregs have several modes of suppressive action at their disposal that may depend on the microenvironment in which the suppressor cells are activated, and may be differentially used to suppress different forms of immunopathology. The secreted factors, such as IL-10 (an inhibitor for dendritic cells) and TGF- $\beta 1$ (which directly act on $\mathrm{T}$ cells) participate in the suppressive action. B7-H3 reportedly costimulates the proliferation of both $\mathrm{CD}^{+}$and $\mathrm{CD}^{+} \mathrm{T}$ cells, enhances the induction of cytotoxic $\mathrm{T}$ cells, and selectively stimulates IFN $\gamma$ production in the presence of $\mathrm{T}$ cell receptor signaling (14). In contrast, inclusion of antisense B7-H3 oligonucleotides decreases the expression of $\mathrm{B} 7-\mathrm{H} 3$ on dendritic cells and inhibits IFN $\gamma$ production by dendritic cell-stimulated allogeneic $\mathrm{T}$ cells. The over-expression of B7-H3 and B7-H4 induce T cells to secrete TGF- $\beta 1$ and the immunosuppressive cytokines IL-2, IL-6, and IL-17 (31). The authors concluded that TGF- $\beta 1$ leads to $\mathrm{T}$ cell-mediated tumor evasion through the increased expression of B7-H3 and B7-H4.

In this study, high counts of CD276 ${ }^{+}$TILs were linked with high levels of TNF- $\alpha$ and IFN $\gamma$ in the preoperative serum, and high counts of Foxp $3^{+}$TILs were linked with the preoperative high serum level of TGF- $\beta 1$. These three cytokines were compared with the clinical course as candidate prognosis predictors. High serum levels of TNF- $\alpha$ and TGF- $\beta 1$ were significantly correlated with the higher risk of recurrence. 
Table III. Correlation between the peritumoral immune associated antigens (CD276 and Foxp3) and preoperative serum levels of cytokines.

\begin{tabular}{|c|c|c|c|c|c|c|}
\hline \multirow[b]{2}{*}{ Variables } & \multicolumn{3}{|c|}{ CD276 } & \multicolumn{3}{|c|}{ Foxp3 } \\
\hline & Low & High & P-value & Low & High & P-value \\
\hline Total $\mathrm{n}$ & 36 & 51 & - & 53 & 34 & - \\
\hline TNF $\alpha$, median (range) & $0.024(0.016-0.072)$ & $0.058(0.016-0.49)$ & 0.03 & $0.049(0.016-0.49)$ & $0.036(0.016-0.16)$ & 0.19 \\
\hline TGF $\beta$, median (range) & $0.066(0.15-1.19)$ & $0.065(0.098-1.18)$ & 0.57 & $0.61(0.15-1.18)$ & $0.71(0.098-1.19)$ & 0.02 \\
\hline IFN $\gamma$, median (range) & $0.031(0.018-0.070)$ & $0.034(0.015-0.082)$ & 0.04 & $0.031(0.015-0.078)$ & $0.034(0.018-0.082)$ & 0.32 \\
\hline IL-6, median (range) & $0.71(0.071-3.80)$ & $0.66(0.071-3.82)$ & 0.23 & $0.66(0.071-3.82)$ & $0.71(0.073-3.80)$ & 0.38 \\
\hline IL-10, median (range) & $0.11(0.023-0.88)$ & $0.018(0.019-3.33)$ & 0.39 & $0.11(0.019-1.43)$ & $0.20(0.023-3.33)$ & 0.18 \\
\hline IL-17, median (range) & $0.11(0.025-1.28)$ & $0.12(0.025-1.06)$ & 0.82 & $0.090(0.025-0.80)$ & $0.15(0.025-1.28)$ & 0.95 \\
\hline
\end{tabular}

Mann-Whitney U test, with units of pg/ml. TNF, tumor necrosis factor; TGF, transforming growth factor; IFN, interferon; IL, interleukin.
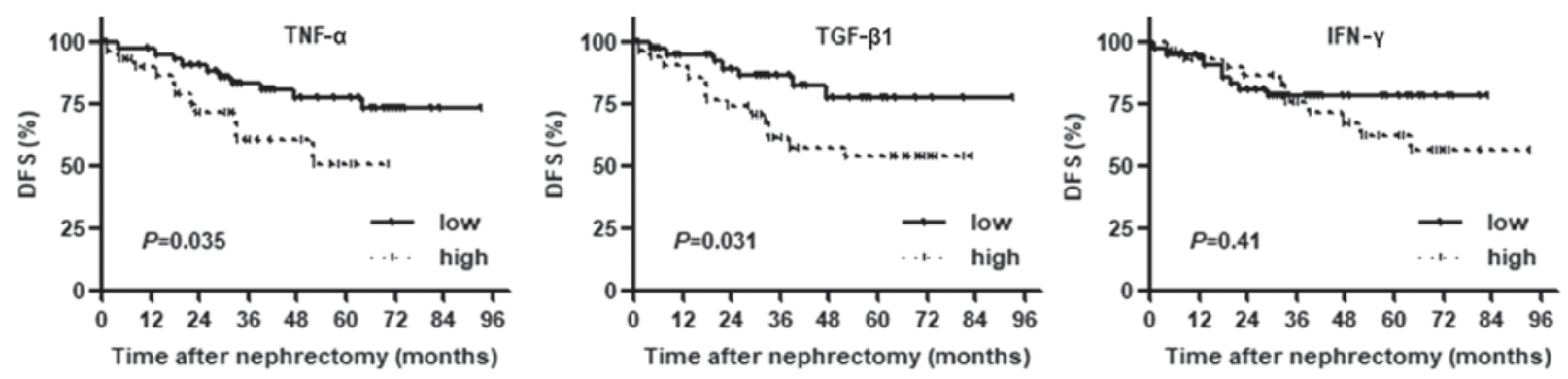

Figure 3. Kaplan-Meier curves for disease-free survival in all 87 cases. Patients with high serum levels of TNF- $\alpha$ and TGF- $\beta 1$ had a significantly higher risk of recurrence than patients with low serum levels. TNF, tumor necrosis factor; TGF, transforming growth factor; IFN, interferon; DFS, disease-free survival.

One possible scenario is that tumor cells increase the production of TNF- $\alpha$ and TGF- $\beta 1$ to help tumor cells progress. Tumor cells may increase the expression of $\mathrm{B} 7-\mathrm{H} 3$ and promote differentiation from $\mathrm{T}$ cells to Tregs. As a result, the production of TNF- $\alpha$ and TGF- $\beta 1$ are increased, which may support the immune escape and progression of tumor cells.

Moreover, based on the present results, it can be suggested that in patients with high serum levels of TNF- $\alpha$ and TGF- $\beta 1$, the topical immunoreaction in the tumor site might have some kind of influence on systemic immunoreactions preoperatively, leading to poor prognosis in patients. Thus, preoperative serum levels of TNF- $\alpha$ and TGF- $\beta$ could be good candidate risk stratification biomarkers of localized ccRCC.

Some limitations exist in this study. First, this study was a retrospective design, had a relatively small number of cases, and the follow-up period was short. The findings need further validation in forthcoming studies in prospective controlled large sampled clinical trials. Secondly, we described one possible scenario for the progression of tumor cells, but we did not inspect these results in animal or cell experiments. In addition, other types of TILs and cytokines were not evaluated. Further studies should inspect the processes via in vivo or in vitro studies, and evaluate other types of TILs and cytokines.

In conclusion, our findings have demonstrated the possible association of topical intratumoral immunoreaction and systemic immune status in patients with localized RCC. The topical induction of the $\mathrm{CD}_{276^{+}}$and Foxp3 ${ }^{+}$TILs was suggested to be linked with high levels of serum TNF- $\alpha$ and IFN- $\gamma$. Preoperative serum levels of TNF- $\alpha$ and TGF- $\beta$ could be simple and non-invasive biomarkers for risk stratification before radical surgery.

\section{Acknowledgements}

Not applicable.

\section{Funding}

No funding was received.

\section{Availability of data and materials}

The datasets used and/or analyzed during the current study are available from the corresponding author on reasonable request.

\section{Author's contributions}

$\mathrm{KI}, \mathrm{MM}$ and KF contributed to the design of study and writing of the manuscript. KO, SH, YM, DG, YI, and SO conducted the molecular biology studies. YN, SA and NT performed the statistical tests. MM and KF assisted with the writing of the manuscript. All authors read and approved the final manuscript.

\section{Ethics approval and consent to participate}

The Ethics Committee of the Nara Medical University (Nara, China) approved this protocol. (Project identification code: 
1630, accepted: August 21, 2017). All subjects gave their written informed consent for inclusion before they participated in the study.

\section{Patient consent for publication}

All subjects gave their informed consent for inclusion before they participated in the study.

\section{Competing interests}

The authors declare that they have no competing interests.

\section{References}

1. Rini B, Campbell SC and Escudier B: Renal cell carcinoma. Lancet 373: 1119-1132, 2009.

2. Eggener SE, Yossepowitch O, Pettus JA, Snyder ME, Motzer RJ and Russo P: Renal cell carcinoma recurrence after nephrectomy for localized disease: Predicting survival from time of recurrence. J Clin Oncol 24: 3101-3106, 2006.

3. Miyake M, Kuwada M, Hori S, Morizawa Y, Tatsumi Y, Anai S, Hosokawa Y, Hayashi Y, Tomioka A, Otani T, et al: The best objective response of target lesions and the incidence of treatment-related hypertension are associated with the survival of patients with metastatic renal cell carcinoma treated with sunitinib: A Japanese retrospective study. BMC Res Notes 9: 79, 2016.

4. Bromwich EJ, McArdie PA, Canna K, McMillan DC, McNicol AM, Brown M and Aitchison M: The relationship between T-lymphocyte infiltration, stage, tumor grade and survival in patients undergoing curative surgery for renal cell cancer. Br J Cancer 89: 1906-1908, 2003.

5. Webster WS, Lohse CM, Thompson RH, Dong H, Frigola X, Dicks DL, Sengupta S, Frank I, Leibovich BC, Blute ML, et al: Mononuclear cell infiltration in clear-cell renal cell carcinoma independently predicts patient survival. Cancer 107: 46-53, 2006.

6. Uzzo RG, Rayman P, Kolenko V, Clark PE, Bloom T, Ward AM Molto L, Tannenbaum C, Worford LJ, Bukowski R, et al: Mechanisms of apoptosis in T cells from patients with renal cell carcinoma. Clin Cancer Res 5: 1219-1229, 1999.

7. Rayman P, Wesa AK, Richmond AL, Das T, Biswas K, Raval G, Storkus WJ, Tannenbaum C, Novick A, Bukowski R and Finke J: Effect of renal cell carcinomas on the development of type 1 T-cell responses. Clin Cancer Res 10: 6360S-6366S, 2004.

8. Condeelis J and Pollard JW: Macrophages: Obligate partners for tumor cell migration, invasion, and metastasis. Cell 124 263-266, 2016

9. Schreiber RD, Old LJ and Smyth MJ: Cancer immunoediting: Integrating immunity's roles in cancer suppression and promotion. Science 311: 1565-1570, 2011.

10. Maxilloux AW and Young MR: Regulatory T-cell trafficking: From thymic development to tumor-induced immune suppression. Crit Rev Immunol 30: 435-447, 2010.

11. Liotta F, Gacci M, Frosali F, Querci V, Vittori G, Lapini A, Santarlasci V, Semi S, Cosmi L, Maggi L, et al: Frequency of regulatory $\mathrm{T}$ cells in peripheral blood and in tumour-infiltrating lymphocytes correlates with poor prognosis in renal cell carcinoma. BJU Int 107: 1500-1506, 2011.

12. Ye Z, Zheng Z, Li X, Zhu Y, Zhong Z, Peng L and Wu Y: B7-H3 overexpression predicts poor survival of cancer patients: A meta-analysis. Cell Physiol Biochem 39: 1568-1580, 2016.

13. Fukuda T, Kamai T, Masuda A, Nukui A, Abe H, Arai K and Yoshida K: Higher preoperative serum levels of PD-L1 and B7-H4 are associated with invasive and metastatic potential and predictable for poor response to VEGF-targeted therapy and unfavorable prognosis of renal cell carcinoma. Cancer Med 5: 1810-1820, 2016

14. Chapoval AI, Ni J, Lau JS, Wilcox RA, Flies DB, Liu D, Dong H, Sica GL, Zhu G, Tamada K and Chen L: B7-H3: A costimulatory molecule for $\mathrm{T}$ cell activation and IFN-gamma production. Nat Immunol 2: 269-274, 2001.
15. Anthony LD, Richard ML and Miranda R: Immunity: The immune response in infectious and inflammatory disease. New Sci Press: 387, 2007.

16. Sobin LH, Gospodarowicz MK and Wittekind $\mathrm{CH}$ (eds): International union against cancer. UICC TNM classification of malignant tumors. 7th edition. Wiley-Liss, pp255-257, 2009.

17. Frank I, Blute ML, Cheville JC, Lohse CM, Weaver AL and Zincke $\mathrm{H}$ : An outcome prediction model for patients with clear cell renal cell carcinoma treated with radical nephrectomy based on tumor stage, size, grade and necrosis: The SSIGN score. J Urol 168: 2395-2400, 2002

18. Fuhman SA, Lasky LC and Limas C: Prognostic significance of morphologic parameters in renal cell carcinoma. Am J Surg Pathol 6: 655-663, 1982.

19. Thompson RH, Gillett MD, Cheville JC, Lohse CM, Dong H, Webster WS, Chen L, Zincke H, Blute ML, Leibovich BC and Kwon ED: Costimulatory molecule B7-H1 in primary and metastatic clear cell renal cell carcinoma. Cancer 15: 2084-2091, 2005.

20. Li L, Yang C, Zhao Z, Xu B, Zheng M, Zhang C, Min Z, Guo J and Rong R: Skewed T-helper (Th)1/2- and Th17/T regulatory-cell balances in patients with renal cell carcinoma. Mol Med Rep 11: 947-953, 2015.

21. Petersen RP, Campa MJ, Sperlazza J, Conlon D, Joshi MB, Harpole DH Jr and Patz EF Jr: Tumor infiltrating Foxp $3^{+}$regulatory T-cells are associated with recurrence in pathologic stage I NSCLC patients. Cancer 107: 2866-2872, 2006.

22. Bates GJ, Fox SB, Han C, Leek RD, Garcia JF, Hamis AL and Banham AH: Quantification of regulatory T cells enables the identification of high-risk breast cancer patients and those at risk of late relapse. J Clin Oncol 24: 5373-5380, 2006.

23. Fu J, Xu D, Liu Z, Shi M, Zhao P, Fu B, Zhang Z, Yang H, Zhang $\mathrm{H}$, Zhou $\mathrm{C}$, et al: Increased regulatory $\mathrm{T}$ cells correlate with CD8 T-cell impairment and poor survival in hepatocellular carcinoma patients. Gastroenterology 132: 2328-2339, 2007.

24. Hiraoka N, Onozato K, Kosuge T and Hirohashi S: Prelavence of Foxp $3^{+}$regulatory cells increases during the progression of pancreatic ductal adenocarcinoma and its premalignant lesions. Clin Cancer Res 12: 5423-5434, 2006.

25. Curiel TJ, Coukos G, Zou L, Alvarez X, Cheng P, Mottram P, Evdemon-Hogan M, Conejo-Garcia JR, Zhang L, Burow M, et al: Specific recruitment of regulatory $\mathrm{T}$ cells in ovarian carcinoma fosters immune privilege and predicts reduced survival. Nat Med 10: 942-949, 2004.

26. Polimeno M, Napolitano M, Costantini S, Portella L, Esposito A, Capone F, Guerriero E, Trotta A, Zanotta S, Pucci L, et al: Regulatory T cells, interleukin (IL)-6, IL-8, vascular endothelial growth factor (VEGF), CXCL10, CXCL11, epidermal growth factor (EGF) and hepatocyte growth factor (HGF) as surrogate markers of host immunity in patients with renal cell carcinoma. BJU Int 112: 686-696, 2013.

27. Sun Y, Wang Y, Zhao J, Gu M, Giscombe R, Lefvert AK and Wang X: B7-H3 and B7-H4 expression in non-small-cell lung cancer. Lung Cancer 53: 143-151, 2006.

28. Sun J, Chen LJ, Zhang GB, Jiang JT, Zhu M, Tan Y, Wang HT, $\mathrm{Lu} \mathrm{BF}$ and Zhang XG: Clinical significance and regulation of the costimulatory molecule B7-H3 in human colorectal carcinoma. Cancer Immunol Immunother 59: 1163-1171, 2010.

29. Crispen PL, Sheinin Y, Roth TJ, Lohse CM, Kuntz SM, Frigola X, Thompson RH, Boorjian SA, Dong H, Leibovich BC, et al: Tumor cell and tumor vasculature expression of $\mathrm{B} 7-\mathrm{H} 3$ predict survival in clear cell renal cell carcinoma. Clin Cancer Res 14: 5150-5157, 2008

30. von Boehmer $\mathrm{H}$ : Mechanism of suppression by suppressor $\mathrm{T}$ cells. Nat Immunol 6: 338-344, 2005.

31. Zhou X, Mao Y, Zhu J, Meng F, Chen Q, Tao L, Li R, Fu F, Liu C, $\mathrm{Hu} \mathrm{Y}$, et al: TGF- $\beta 1$ promotes colorectal cancer immune escape by elevating $\mathrm{B} 7-\mathrm{H} 3$ and $\mathrm{B} 7-\mathrm{H} 4$ via the $\mathrm{miR}-155 / \mathrm{miR}-143$ axis. Oncotarget 7: 67196-67211, 2016. 